\title{
REVOLUÇÃo PASSIVA E O PAPEL FORMATIVO DA FILOSOFIA NO ENSINO MÉdIO ${ }^{1}$
}

\section{Passive Revolution and the formative role of PHILOSOPHY IN HIGH SCHOOL}

\author{
Paolo Nosella \\ Docente da Universidade Federal de São Carlos, São Carlos/SP, Brasil \\ nosellap@terra.com.br
}

\begin{abstract}
Alessandra Maria Martins Gaidargi
Doutora em educação pela Universidade Nove de Julho, São Paulo/SP, Brasil alessandra.gaidargi@gmail.com
\end{abstract}

\begin{abstract}
Resumo: Este texto é um estudo em desenvolvimento, um work in progress, em que apresentamos anotações preliminares que serão aprofundadas posteriormente em ensaios. Defendemos que a fecundidade teórica da categoria revolução passiva, que Antonio Gramsci desenvolve nos seus escritos, possibilita análise profunda e crítica da revoluçáo midiática em curso. A primeira parte ilustrará o conceito de revolução passiva em Gramsci; a segunda verterá sobre a revolução passiva na cultura brasileira em geral e, atualmente, sobre a indiscriminada e ampla utilização das mídias pelos jovens estudantes de ensino médio; a terceira defenderá a proposta do ensino da filosofia na escola média como instrumento de reconstrução unitária e responsável da concepção de mundo pelos jovens adolescentes.
\end{abstract}

Palavras-chave: Ensino Médio. Filosofia. Revolução Passiva.

ABSTRACT: This paper is a work in progress, in which we present preliminary notes that will be further developed in essays. We argue that the theoretical fruitfulness of the category "passive revolution" that Antonio Gramsci developed in his writings, provides thorough analysis and critique of the media revolution underway. The first part will illustrate the concept of "passive revolution" Gramsci. The second part will focus on the passive revolution in brazilian culture in general, and currently on the indiscriminate and extensive use of media by young high school students. The third part is a defense of the philosophy education proposed in middle school as an "instrument" of unit and responsible reconstruction of the world's concept for young teens.

Keywords: High School. Philosophy. Passive Revolution. 


\section{Introduçáo}

A natureza deste texto define-se, como diz Rocco Lacorte (2009), como um work in progress, isto é, um trabalho em desenvolvimento no qual apresentam-se anotaçóes preliminares que serão aprofundadas posteriormente em ensaios. Nele, destacamos a fecundidade teórica da categoria revolução passiva que Antonio Gramsci desenvolve nos seus escritos, relacionando-a ao papel formativo da filosofia na reconstrução unitária e responsável da concepção de mundo pelos adolescentes do Ensino Médio.

\section{Oue é revolução passiva?}

Uma primeira aproximação ao conceito de revolução passiva é oferecida pela antológica frase do romance Il gattopardo, de Giuseppe Tomasi di Lampedusa (1958)2: "É preciso mudar tudo para que tudo fique como está”. Essa afirmação traduz, em linguagem literária, a ideia de que muitas reformas ou mudanças sociais ocorrem para que a relação de hegemonia de classe permaneça a mesma. Gramsci percebera que os modernos detentores do poder, de todo matiz ideológico, temiam a guerra de movimento (insurreição violenta ou guerra manobrada), uma vez que os que a deflagram nem sempre serão, ao final da guerra, os novos protagonistas da história.

Com efeito, os movimentos violentos dificilmente são controláveis e 'restaurar' a ordem anterior implica, necessariamente, um processo longo e caro. Por isso, a ciência política moderna estabeleceu forte relação, na luta hegemônica, entre 'guerra de posição', 'revolução-restauração' e 'revolução passiva', categorias fortemente interligadas, mesmo não sendo sinônimos, 'armas' utilizadas em tempos de paz, tanto pelos pretendentes quanto pelos detentores do poder.

Gramsci náo criou o termo revoluçáo passiva. Fundiu a expressão 'revolução-restauração' de Edgar Quinet com a expressão revolução passiva de Vincenzo Cuoco, forjando um novo e original conceito de revoluçáo passiva. No Caderno do Cárcere, se pergunta: 
Deve-se ver se a fórmula do Quinet [revolução-restauração] pode ser aproximada à de 'revolução passiva' do Cuoco; essas [fórmulas] expressam, talvez, o fato histórico da ausência de uma iniciativa popular unitária no desenvolvimento da história italiana e, ainda, o outro fato de o desenvolvimento [progresso] ter ocorrido como reação das classes dominantes à subversão esporádica, elementar e desorganizada das massas populares por meio de 'restauraçôes' que acatam alguma parte das exigências de baixo, logo, 'restauraçóes progressivas' ou 'revoluçóes-restaurações' ou ainda 'revoluções passivas'. (GRAMSCI, 1975, pp. $1324-1325)^{3}$

Portanto, podemos concluir, parafraseando a citação, que a essência do conceito de revolução passiva está na ausência de iniciativa popular no desenvolvimento da história, bem como no fato de o 'progresso' ter ocorrido por meio de revoluçôes-restaurações, isto é, como reação das classes dominantes às esporádicas e desorganizadas revoltas populares. Observese que toda revoluçáo passiva traz profundas, amplas e moleculares mudanças nas populaçôes, com valências ético-políticas muito diferenciadas ou mesmo antitéticas. Basta considerar que tanto a unificação italiana (Risorgimento) quanto o fascismo podem ser consideradas revoluçôes passivas $^{4}$. Enfim, pelas revoluçôes passivas a população é revolucionada, não é revolucionária.

A maior originalidade da tradução, ou elaboração, gramsciana do conceito de revolução passiva consiste na afirmação de que esse tipo de revolução acaba por obter sempre um resultado negativo na formação (educação) das massas populares por aplicar, apesar das aparências, uma 'pedagogia' da passividade. Muito além da primária consideração sobre benefícios ou malefícios que determinada revolução passiva tenha oportunizado para as populaçóes, há o fato de que essa pedagogia da passividade ofusca, teórica e politicamente, na consciência popular, a dialética da formação do Estado e da função dos grupos dirigentes (intelectuais), ou seja, em decorrência dessa 'passividade' teórica e prática o Estado passa a ser concebido como algo em si, um 'absoluto racional', e o grupo inovador (intelectuais), ocultando sua natureza econômica, apresenta-se como uma casta abstrata e autônoma de iluminados. Tudo isso se agrava 
quando o desenvolvimento local, o progresso, reflete o desenvolvimento internacional, que "envia para a periferia suas correntes ideológicas." Vale a pena citar por inteiro o texto:

Quando o impulso para o progresso não é estreitamente ligado a um amplo desenvolvimento econômico local, que é artificialmente limitado e reprimido, sendo reflexo do desenvolvimento internacional que envia para a periferia suas correntes ideológicas nascidas com base no desenvolvimento produtivo dos países mais evoluídos, o grupo portador das novas ideias não é o grupo econômico, mas a camada dos intelectuais, e a concepção do Estado que se divulga muda de aspecto, sendo concebido como uma coisa em si, como um absoluto racional. [...] Essa explicação é fundamental para compreender historicamente o idealismo filosófico moderno e liga-se ao modo de formação dos Estados modernos na Europa continental como forma de "reação-superação nacional" da Revolução Francesa, a qual, com Napoleão, tendia a estabelecer uma hegemonia permanente (motivo essencial para compreender o conceito de "revolução passiva", de "restauração-revolução", e para entender a importância da comparação hegeliana entre os princípios dos jacobinos e a filosofia clássica alemã). (GRAMSCI, 1975, p. 1360)

Dessa antológica citação resumimos três ideias-chave sobre o conceito de revolução passiva: a) ela modifica material e espiritualmente toda a sociedade sem profunda participaçáo dela: a populaçáo pode emprestar seu corpo, ideologicamente empresta sua mente e até seu entusiasmo, em prejuízo de seus mais profundos anseios de liberdade; o mesmo ocorre também entre naçôes periféricas e naçôes evoluídas; b) em consequência dessa pedagogia da passividade, os intelectuais e o Estado passam a ser vistos pela população como realidades abstratas, em si, como absolutos racionais, desvinculados do processo econômico objetivo, e a massa percebe-se metafisicamente distante e dependente dos centros do poder; c) há conexão íntima entre as revoluçóes-passivas e as revoluçóes-restauraçóes, no sentido de as primeiras funcionarem 
como restauração da antiga ordem ameaçada por eventuais ou possíveis revoluçóes ativas.

\section{Revoluçáo passiva e o Brasil}

Todo o desenvolvimento do Brasil pode ser lido à luz da categoria revoluçáo passiva. Com efeito, poucas sociedades têm sofrido mudanças tão radicais como as primitivas comunidades indígenas brasileiras. Independentemente do fato de que essas mudanças possam ter trazido benefícios ou malefícios, certamente tratou-se de uma inaudita revolução passiva (do alto e de fora), que os habitantes locais consideraram de natureza 'transcendental'.

Sugestiva é, nesse sentido, a metáfora utilizada por Arno Wehling (2005, p. 45), "os sucessivos avatares", ao referir-se às incorporaçôes do Brasil ao mundo moderno. Avatar, sendo manifestação corporal de um ser supremo, uma 'descida' do alto, denota encarnaçôes onde o 'corpo' obedece e se submete ao ser externo, superior. Assim, o primeiro avatar foi, pela triagem ibérica, o catolicismo contrarreformista. Na continuidade, outros avatares: o Iluminismo, o Liberalismo, o Romantismo, todos movimentos que aceleraram o capitalismo visando superar a condição brasileira de país atrasado. Sub-repticiamente, reforçavam "o sentimento de incompletude em relação ao modelo externo, ponto teleológico que deveria ser atingido.” (WEHLING, 2005, p. 46-47)

A própria Independência do Brasil foi um movimento de revolução passiva. Se para a casta dos intelectuais foi reflexo do iluminismo industrial, para a massa popular foi mudança vinda da corte, do alto e de fora, 'para inglês (ou francês) ver'. Prova disso é que os mesmos nomes da elite do Império (ancien régime) permaneceram na direção da República. Isto é, tudo mudara para que nada mudasse, como retrata, com humor, o conto de Arthur de Azevedo O velho Lima, no qual esse antigo funcionário adoece e se afasta do trabalho justamente no dia 14 de novembro de 1889, véspera da Proclamação da República, e, de volta à sua seção de trabalho, no dia 23 de novembro, "como nada lhe disseram (porque nada sabiam), ignorava completamente que o Império se transformara em República." (AZEVEDO, 2002, p. 48) 
É importante sublinhar que as revoluçóes passivas devem ser consideradas em suas diferentes graduaçôes, conforme as circunstâncias, os segmentos da população envolvida e a direção geral da história. Por exemplo, tanto o Brasil populista e corporativo (que sindicalizou, mas também iludiu a população) quanto os governos militares (que modernizaram, mas também massacraram) e, ainda, a Nova República (que encheu as estradas de carros e as casas de aparelhos eletrônicos, mas condenaram as pessoas a viverem entrincheiradas em condomínios fechados ou em solitárias residências com altos muros, grades e arames farpados), são produtos de revoluções passivas, apresentando, porém, características diferenciadas.

$\mathrm{Na}$ contemporaneidade, muitas coisas mudaram: os campos se esvaziaram, as cidades incharam e, sobretudo, foram construídos muitos imensos shoppings - luminosos, luxuosos, atraentes, mágicos - que ladeiam pobres escolas, miseráveis hospitais e inúmeros salóes-igrejas a comercializar sentidos.

\section{A revoluçáo passiva das mídias e o estudante de Ensino Médio}

Assim, infelizmente, as massas dos trabalhadores e dos jovens regressaram à velha ordem, vencidos pelos sonhos de consumo, pelos carros e motos, pelos tênis importados e pelos inúmeros aparelhos eletrônicos. Particularmente os jovens, alojados nas periferias das metrópoles, foram fulminados pelo brilho 'metafísico' do mercado. Ao procurarem se adequar ao padráo imposto pelo consumo moderno, colhem frustração sobre frustração. Ouviram falar, de longe, de antigas lutas sociais que derrubaram os governos militares. Cegos, e infinitamente insatisfeitos, frequentemente perdem-se numa pseudo-dialética de luta política, colocando-se contra tudo, sem perceber que a recusa absoluta que não aponta caminhos abre as portas ao que der e vier: "A rejeição pura é árida e má. Dessa forma, pela mera recusa, os jovens encontram-se parados na história." (PASOLINI, 2014, p. 283)

No mundo sedutor dos shoppings brilha a sedução das mídias: ver tudo, saber tudo, conhecer tudo, relacionar-se com todos, sempre, em 
tempo real. Para alguns é o antigo poder da onipresença, que vê e acompanha tudo sempre, sem esforço, magicamente. Para outros é a tentação diabólica e consumista de Cristo no deserto: "Todas estas coisas te darei, se, prostrado, me adorares.” (MATEUS, 1970, p. 14)

Certamente estamos presenciando uma 'revolução', mas qual é sua natureza?

Certa vez um professor de filosofia do Ensino Médio da rede pública estadual nos procurou com uma inquietação presente em seu trabalho de pesquisa: de acordo com ele a conversa paralela em sala de aula vinha ganhando cada dia mais espaço, o que em sua opinião se devia em grande parte ao advento das novas mídias e dos celulares. Este professor chamava estas conversas paralelas de falas, falas de toda ordem, que comumente eram consideradas como indícios de indisciplina. A seu ver, eram inadequadas, não condiziam com a situação e ambiente social, ou eram apenas falas muito rasas sobre questóes que mereciam maior atenção. E na inquietação deste professor reconhecemos a de tantos outros que faziam esta mesma referência, com frequência, às falas paralelas dos alunos.

Contudo, são falas e, como tal, expressão de algo. Mas, a escola tem a sua fala oficial e, de certa forma, esta fala atende a uma lógica da preparação para o mercado de trabalho, tão caro para certos setores da sociedade. Evidentemente, aquelas falas dos estudantes continuam apenas como falas indisciplinadas.

As falas, para Gramsci, enquanto linguagem, são "expressão viva da concepção de vida, do senso comum popular, da cultura em geral. É o instrumento fundamental da filosofia da práxis, da educação, da escola e, sobretudo, da hegemonia política." (NOSELLA, 2018, p.18). Essa linguagem, de acordo com Gramsci, é algo próprio dos adultos? De quaisquer adultos? Da sociedade como um todo? Os jovens também possuem uma linguagem a ser considerada?

Tenho comigo que esse é o tema central da escola atual. Potencializar a prática da fala em algo que contribua com a emancipação e a transformação social. Aí reside a presença da filosofia e do professor de filosofia com sua prática pedagógica.

O uso de aparelhos tecnológicos em ambiente escolar é uma realidade com a qual os professores precisam lidar na atualidade e que, 
muitas vezes, gera intensos debates entre o corpo discente e docente, em especial no que diz respeito aos limites dessa utilização. $\mathrm{O}$ jovem hoje se comunica com toda a sociedade sem necessitar de permissão ou supervisão para isso. "Ele o faz por meio do computador, do celular, do SMS, dos chats, dos jornais, da própria televisão (que já abre espaço para a participação da audiência em muitos programas).” (GAIDARGI, 2013, p.15)

A discussão sobre educação para as mídias no Ensino Médio ganha espaço na atualidade exatamente pela necessidade de considerarmos o uso e a produção de mídia como atividades cotidianas do jovem, independentemente de localização ou classe social. A expansão e o largo uso das mídias e da tecnologia midiática nessas últimas décadas tornaram a presença de celulares e smartphones algo intrínseco à vida social do jovem, considerado inclusive como atividade natural.

A escola, em geral, apresenta as mídias como ferramentas a serem consideradas e exploradas tão somente para " [...] conectar os inúmeros conhecimentos com suas aplicaçóes tecnológicas.” (NUNES, 2000, p. 112) Com efeito, a comunicação virtual oferece uma enorme quantidade de opçóes para os jovens estudantes e a oferta de conteúdo é acessível a qualquer dia da semana e horário: "A presença dos meios é dinâmica: percorre do internacional, ao nacional, ao local; do individual, ao particular, ao genérico, entrelaçando-os, num movimento permanente de ir e vir. E enlaçando-nos.” (BACCEGA, 1997, p.35). Isto faz com que a escola e o tipo de educação que sáo oferecidos aos jovens precisem ser repensados, a fim de se tornarem tấo ou mais interessantes do que as possibilidades de entretenimento propiciadas por essas mídias, tornando o processo de aprendizagem de fato integrado ao ambiente virtual mundial e, assim, ultrapassando o acesso às mídias como papel coadjuvante ou auxiliar:

A maneira com que ensinamos e aprendemos vive um momento crucial de mudança, que já vem sendo previsto nos últimos documentos oficiais, mas que ainda não foi incorporada pela escola brasileira no Século XXI. O antigo modelo de aula expositiva, sem interação entre professores e alunos, simplesmente não atende às necessidades de transformação 
crescentes a cada dia. [...] A escola de Ensino Médio terá de ser, em algumas de suas diretrizes, reinventada. (GAIDARGI, 2013, p.158)

Essa abordagem abre as portas para outra discussão, mais ampla e mais antiga, sobre a necessidade da integração entre o mundo escolar e o mundo real do jovem, na busca por um Ensino Médio emancipatório e integrado à sociedade. $\mathrm{O}$ uso da internet para comunicar-se com outros jovens ou navegar pelo mundo virtual não é o único atrativo trazido pela tecnologia. A possibilidade de acompanhamento das mídias ditas tradicionais, como a programação da televisão aberta e das rádios, pelos celulares e smartphones aumenta o contingente de diversidade de entretenimentos, específicos ou não, para o jovem, oferecidos virtualmente, que disputam espaço com a informação escolar. Atualmente, todas as grandes emissoras contam com suporte virtual e interativo para a retransmissão de sua programação em tempo real.

Se os alunos do Ensino Médio que encontramos em nossas salas de aula não tivessem sido educados, desde a infância, com amplo e muitas vezes irrestrito acesso aos mais diversos aparelhos tecnológicos, poderíamos discutir sobre a inserção deles no meio escolar ou sobre qual seriam os aspectos positivos e negativos dessa inserção antes de efetivamente torná-la disponível a eles. Entretanto, a revolução das mídias inseriu, de forma passiva e inadvertidamente, inúmeros aparelhos midiáticos na vida dos jovens. A despeito de suas consequências, a escola precisa considerar que esta é a realidade atual, ainda que sua forma de ser não tenha sido demandada por esses jovens ou por seus pais. A respeito do modelo de educaçáo que se aparta da tecnologia, "não está claro se esse era o melhor modelo cem anos atrás; e, se era, com certeza não é mais. Nesse meio tempo, novas tecnologias oferecem esperança de meios mais eficazes de ensino e aprendizagem [...]" (KHAN, 2013, p.9)

O tom não é apocalíptico, prevendo o fim dos tempos da educação como a conhecemos, mas é de advertência para que haja uma formação crítica para essa revolução passiva das mídias, pois ela já está ocorrendo. 


\section{Consideraçóes conclusivas: a formação filosófica dos adolescentes}

Os jovens têm certamente uma linguagem própria e a mídia contribuiu para a formação da mesma. A categoria gramsciana de revoluçáo passiva pode servir para auxiliar na análise desse fenômeno, pois a "revolução" das mídias representa, de um lado, muitas mudanças positivas, sabemos; mas, de outro lado, opera também transformações que podem tornar os alunos uma massa intelectual e moralmente passiva, desagregada, sem condiçôes de processar análises profundas e críticas do que está ocorrendo, dificultando, com isso, opçôes ético-filosóficas livres, responsáveis e coerentes.

Aqui entra em cena o importante papel formativo da filosofia e, portanto, do ensino de filosofia aos jovens adolescentes de nível médio, fase escolar da maturidade e da autonomia. A preocupação expressa no email citado acima tem fundamento: a formação filosófica tem grande conexão com linguagem, uma vez que pensar filosoficamente não é operação mental autônoma, elaboração individual. Exige, sim, esforço de disciplina individual, mas é, sobretudo, uma luta coletiva e dialética entre mestre e aluno, entre geração mais velha e mais nova, para a conquista de um mesmo clima cultural, ou seja, de uma mesma linguagem (não tanto de uma mesma língua).

Pelo exercício filosófico, o jovem aluno, ainda um frankenstein ${ }^{5}$ filosófico, será levado a inventariar sua filosofia espontânea, resultado caótico e passivo de inúmeros fragmentos despejados pelas mídias e por todas as relações que o envolveram desde o berço. A disciplina do estudo filosófico não tornará o aluno, de forma automática, melhor, mas certamente contribuirá na organização de seu pensar, desse modo elevando sua responsabilidade frente às opçóes tomadas por colocá-lo de forma ativa e autônoma diante de um horizonte de observação mais aberto.

No atual clima cultural, fortemente excitado pelas mídias que, em tempo real, arremessam e impóem infinitos fragmentos e opinióes de todas as culturas, de todas as pessoas e em todas as direçóes, o exercício do pensar filosófico contribui com os jovens adolescentes na resposta à pergunta que nos aflige a todos: é possível projetar e construir um sistema de saberes e de valores, básico e universal, no qual todas as 


\section{culturas possam se encontrar, preservando as diferenças identitárias de cada linguagem?}

\section{Notas}

1 Texto apresentado como comunicação no $5^{\circ}$ Congresso da Sociedade de Filosofia da Educação de Língua Portuguesa (SOFELP), realizado na UNICAMP, de 26 a 28 de agosto de 2015.

2 Com base nesse romance, foi produzido o filme homônimo, premiado em 1963, do diretor italiano Luchino Visconti.

3 As traduções do original italiano são de nossa autoria.

4 A fecundidade teórica do conceito gramsciano de revolução passiva e sua tradutibilidade para o momento histórico atual, de intensificação do modelo capitalista, são atualmente testemunhadas por muitos trabalhos ensaísticos, literários, cinematográficos e artísticos em geral. Citamos o exemplo do romance póstumo e inacabado de Pier Paolo Pasolini, Petrolio, monumental satyricon moderno, cujas páginas retratam as pessoas, jovens sobretudo, desta sociedade atual do consumismo, vítimas de mudanças impostas de fora e do alto: "Os velhos clérigo-fascistas reergueram a cabeça, e um clima de restauração soprou como um ventou quente e úmido na Itália. (...) A única realidade que pulsa com o ritmo e angústia da verdade é aquela - impiedosa - da produção, da defesa da moeda, da manutenção das velhas instituiçóes ainda essenciais ao novo poder e não, certamente, das escolas, nem dos hospitais, nem das igrejas. (...) O modelo é único: é aquele que o centro, por meio da imprensa e da televisão, molemente impóe.” (PASOLINI, 2014, p. 282-283-284) Rocco Lacorte (2008, p. 88), comentando, escreve: "Se, em Petrolio, o nome do intelectual Sardo (Gramsci) não aparece, suas ideias, de alguma forma, aí vivem e circulam como um rio subterrâneo."

5 Referência ao personagem literário criado por Mary Shelley (1818), composto de forma fragmentada por partes de outros seres humanos, se tornando uma criatura de características misturadas.

\section{Referências}

AZEVEDO, Arthur. O velho Lima. In: NOSELLA, Paolo. Qual compromisso politico? Bragança Paulista: EDUSF, 2002.

BACCEGA, Maria Aparecida. Comunicação na educação formal: processo de mudança. In: Revista Comunicação \& Educação, São Paulo, mai/ago, 1997.

GAIDARGI. Alessandra M. M. Educação para as mídias no Ensino Médio: perspectivas para o século XXI. 2013. 204 f. Dissertação (Mestrado em Educação) - Universidade Nove de Julho - UNINOVE, São Paulo.

GRAMSCI, Antonio. Quaderni del cárcere. Edição crítica do Instituto Gramsci de Valentino Gerratana. Torino: Einaudi Editora, 1975.

KHAN, Salman. Um mundo, uma escola. Rio de Janeiro: Intrínseca, 2013.

LAMPEDUSA, Giuseppe Tomasi. Il gattopardo. Torino: Einaudi, 1957. 
MATEUS, in: Novo Testamento. São Paulo: Editora Herder, 1970.

NOSELLA, Paolo. A escola de Gramsci. São Paulo: Cortez, 2018.

NUNES, Clarice. Ensino médio. Rio de Janeiro: DP\&A, 2002.

PASOLINI, Pier Paolo. Petrolio. Milão: Arnoldo Mondadori, 2014.

WEHLING, Arno. A incorporação do Brasil ao mundo moderno. In: STEPHANOU, Maria; BASTOS, Maria Helena Câmara (Org.). Histórias e memórias da educação no Brasil. vol. I - séculos XVI-XVIII. Petrópolis: Editora Vozes, 2005.

Recebido em I7 mai. 2018 / Aprovado em I5 out. 2018

\section{Para referenciar este texto:}

NOSELLA, P.; GAIDARGI, A. M. M. Revolução passiva e o papel formativo da filosofia no Ensino Médio. EccoS - Revista Científica, São Paulo, n. 47, p. 289-300. set/dez. 2018. Disponível em: <https://doi.org/10.5585/EccoS.n47.6020>. 